\title{
HIPERTEXTOS E GÊNEROS DIGITAIS: CONCEITOS E CARACTERÍSTICAS
}

\section{ARTIGO ORIGINAL}

MEYER, Antonia Izabel da Silva ${ }^{1}$

MEYER, Antonia Izabel da Silva. Hipertextos e Gêneros Digitais: Conceitos e características. Revista Científica Multidisciplinar Núcleo do Conhecimento. Ano 05, Ed. 10, Vol. 15, pp. 87-108. Outubro de 2020. ISSN: 2448-0959, Link de acesso: https://www.nucleodoconhecimento.com.br/educacao/generos-digitais

\section{RESUMO}

Este estudo objetiva analisar as definições dos hipertextos e as características que eles representam, bem como as novas percepções que surgem a partir da leitura e da escrita em ambientes propícios para o gênero digitais. Com o advento da Internet, surgem os hipertextos, por meio de links que se conectam com textos e levam os usuários a um oceano de informações, por meio de uma leitura não linear. Tais gêneros modificam nossas práticas de ler e de escrever nesses ambientes e evidenciam a integração nesse âmbito. Utilizou-se, como metodologia, uma pesquisa bibliográfica em livros e artigos científicos com autores relacionados a esta temática. Isso resulta na percepção da interatividade do hipertexto e da interação que os gêneros digitais proporcionam na construção do conhecimento.

Palavras-Chave: Educação, hipertextos, gêneros digitais.

${ }^{1}$ Doutorando em Ciências da Educação pela Universidad Autónoma de Asunción UAA, com Mestrado em Ciências da Educação pela UDS, 2017, especialista em MBA em Gestão de Pessoas pela FJN, 2010. 


\section{INTRODUÇÃO}

Com o surgimento da Internet, no final dos anos 1960, nos Estados Unidos, e sua popularização, a partir de dos anos 1990 expandiram-se as possibilidades de acesso à informação de qualquer lugar e a qualquer momento. Por meio de ambientes virtuais, como sites e links, os quais permitem um novo acesso a textos, com sons e imagens, o chamado hipertexto, que constitui a base da Internet, proporciona uma maior interatividade entre o autor e o leitor.

Em primeira análise, convém ressaltar que essas tecnologias têm determinado uma nova modalidade de leitura, escrita e interação. Como o espaço da escrita está relacionado aos gêneros textuais, compreendemos que esses novos espaços de escrita proporcionam o surgimento de novos gêneros.

Com a evolução tecnológica, os novos suportes e gêneros são adaptados, permitindo surgir, assim, novos gêneros e ambientes, o que transforma as práticas de leitura e escrita dos usuários nesses espaços.

Esta pesquisa tem como objetivo analisar as definições dos hipertextos, assim como suas características e as novas percepções a partir da leitura e escrita em ambientes de gêneros digitais. Para tanto, foi realizado um levantamento bibliográfico em livros e artigos científicos publicados sobre o tema, "utilizando o conhecimento disponível a partir das teorias publicadas em livros ou obras congêneres" (KÖCHE, 2011, p.122).

\section{HIPERTEXTOS}

O termo hipertexto foi criado pelo americano Theodore Nelson, na década de 1960, que pensou na possibilidade de mover parte do texto e editá-lo. Esse falto representou, assim, uma escritura eletrônica não sequencial e não linear, a qual se bifurca e permite ao leitor o acesso a um número praticamente ilimitado de outros textos, a partir de escolhas locais e sucessivas em tempo real (MARCUSCHI, 1999).

Nesse ínterim, a difusão do hipertexto digital surgiu com o advento da Internet. Diariamente, vê-se pessoas de todos os países acessarem sites para ler alguma 
coisa, sem necessariamente saber que essas práticas de acesso a determinados links as tornam participantes de uma nova prática de ler e escrever no ambiente digital, que as leva a caminhos possíveis e também não planejados, através de site em uma leitura não linear.

Para Koch (2003), o termo hipertexto designa um processo de escrita/leitura não sequencial e não linear, que permite ao leitor virtual o acesso praticamente ilimitado de outros textos de forma instantânea, através de links que levam a outras páginas na construção do conhecimento.

A esse respeito, Marcuschi (1999, p. 2) ao abordar hipertexto, entende-o como um processo de escritura/leitura eletrônica multilinearizada, multissequencial e indeterminada, que introduz um novo espaço de escrita: a escrita eletrônica. Já Xavier (2002, apud KOMESU, 2005, p. 8) concebe hipertexto como:

Dispositivo 'textual' digital multimodal e semiolinguístico (dotado de elementos verbais, imagéticos e sonoros), disponibilizado na Internet em um endereço eletrônico, e que se encontra interligado a outros hipertextos mediante os hiperlinks (links) que o constituem.

Para esse autor, o hiperlink é a ideia motriz do hipertexto, uma vez que se trata de um dispositivo que possibilita a relação de hipertextos de maneira não sequencial, arbitrária. Araújo (2008) se utiliza das explicações de Octávio Álvares para definir hipertexto como:

Um documento eletrônico composto de nodos ou de unidades textuais interconectados que forma uma rede de estrutura não-linear. Diante dessa estrutura, o leitor tem a possibilidade de delinear suas próprias preferências e caminhos da leitura (ARAÚJO, 2008 p. 4).

Com a leitura não linear do hipertexto, o leitor define a trajetória que quer seguir. A esse respeito, Fachinetto (2005) define hipertexto como um documento digital composto por vários blocos de texto interconectados através de links, que possibilitam - avanço da leitura de forma aleatória, $\mathrm{Na}$ Web, cada endereço pode ser compreendido como um nó da rede, e os links podem remeter tanto às páginas de um mesmo site quanto para outro. 
Bairon (1995, p. 33) afirma que o hipertexto pode ser definido como "um texto estruturado em rede" ou ainda "uma matriz de textos potenciais" na qual "um texto apresenta-se como uma leitura particular do hipertexto".

As autoras Brasileiro e Martins (2013) configuram hipertexto como "uma rede de segmentos múltiplos interconectados, com previsões de diferentes ligações entre si e de diferentes possibilidades de leitura e de construção do conhecimento", em que o leitor pode acessar links de outros textos relacionados ou não ao assunto em estudo.

Komesu (2005, p. 8) revela que "o hipertexto não é um suporte material ou um único texto, mas uma prática multimodal que envolve os processos de escrita e de leitura atualizados na tela do computador".

Conforme Lévy (2011), o hipertexto é o agenciamento de multimídias interativos e sistemas especialistas que têm em comum características multidimensional, dinâmica e a capacidade de adaptação a situações que tornam a escrita estática e linear. Isso implica os diferentes modos de representação que utilizam o suporte informático, através de redes interligadas, que permitem, por meio de links, o acesso a textos.

A fim de descrever as possibilidades múltiplas do hipertexto, Lévy (2011) propôs caracterizá-lo a partir de seis princípios:

1. Princípio de metamorfose - a rede hipertextual está em constante construção e renovação;

2. Princípio de heterogeneidade - os nós e as conexões de uma rede hipertextual são heterogênicos;

3. Princípio de multiplicidade e de encaixe das escalas - o hipertexto se organiza em um ovo "fractal", ou seja, qualquer nó ou conexão, quando analisado, pode revelar-se como sendo composto por toda uma rede, e assim por diante, indefinitivamente;

4. Princípio de exterioridade - a real não possui unidade orgânica, nem motor interno;

5. Princípio de topologia - no hipertexto tudo funciona por proximidade, por vizinhança; 
6. Princípio de mobilidade dos centros - a rede não tem centro, ou melhor, possui permanentemente diversos centros, que são como pontos luminosos perpetuamente móveis, saltando de um nó para outro (LÉVY, 2011).

Percebe-se, portanto, que o hipertexto é dinâmico, interativo, não linear, está sempre em movimento e ao simples clique de um mouse ele revela uma imensa possibilidade de acesso a links, possibilitando ao leitor/escritor a construção do conhecimento.

No ciberespaço, aplica-se a linguagem verbal e não verbal, fundamentado nos princípios da leitura e da escrita, organizado por meio de uma rede de relações e interações em forma de hipertexto. Vale salientar que, para Lévy (1996, p. 56), essa rede pode ser considerada como: "um texto móvel, caleidoscópico, que apresenta suas facetas, gira, dobra-se e desdobra-se à vontade frente ao texto".

De acordo com Soares (2002), o texto na tela - hipertexto "é escrito e lido de forma multilinear, multissequencial, acionando-se links ou nós que levam para as telas uma multiplicidade de possibilidade, sem que haja uma ordem preferida". Essa definição implica a dimensão que o leitor quiser (SOARES, 2002, p. 150).

Logo, esse cenário é marcado por textos que integram som, imagens, movimentos, linguagem escrita, animação, caracterizado por uma leitura não linear, interativa, intertextual. Ramal (2002, p. 84) observa que:

Estamos chegando à forma de leitura e de escrita mais próximo do nosso próprio esquema mental: assim como pensamos em hipertexto, sem limites para a imaginação de cada sentido dado a uma palavra, também navegamos nas múltiplas vias que o novo texto nos abre, não mais em páginas, mas em dimensões superpostas que se interpenetram e que podemos compor e recompor em cada leitura.

Lévy (2011) entende o hipertexto como um processo de escrita e de leitura não linear e não hierarquizada, visto que tal processo apresenta características que permitem o acesso a outros textos verbais, imagens e sons de maneira ilimitada e instantânea, tornando-o multimidiático. A formação de um hipertexto integra, nesse sentido, um mesmo sistema as modalidades escrita, oral e audiovisual de comunicação humana (CASTELLS, 1999). 
Segundo Bolter (1991), o hipertexto constitui-se como um "texto aberto", ou um "texto múltiplo", caracterizado pelos princípios da não linearidade, interatividade, multicentramento e virtualidade. Essa não linearidade, a interatividade e a espacialidade são as características norteadoras do hipertexto.

As principais características apresentadas para o hipertexto virtual, segundo Koch (2003, p.64) são:

1. Não linearidade (geralmente considerada a característica central);

2. Volatilidade, devida à própria natureza (virtual) do suporte;

3. Espacialidade topográfica, por se tratar de um espaço de escritura/leitura sem limites definido, não hierárquico, nem tópico;

4. Fragmentariedade, visto que não possui um centro regular imanente;

5. Multissemiose, por viabilizar a absorção de diferentes aportes sígnicos e sensoriais numa mesma superfície de leitura (palavras, ícones, efeitos sonoros, diagramas, tabelas tridimensionais);

6. Interatividade, devido à relação contínua do leitor com múltiplos autores, praticamente em superposição em tempo real;

7. Interatividade, em decorrência de sua natureza intrinsecamente polifônica e intertextual;

8. Descentração, em virtude de um deslocamento indefinido de tópicos, embora não se trate, é claro, de um agregado aleatório de fragmentos textuais $(\mathrm{KOCH}, 2003$, p.64)

Essas características tornam o hipertexto um evento virtual, descentralizado e interativo, sem um espaço de leitura e escrita definidos, de modo que permite que o leitor acesse a informação em qualquer lugar do mundo.

Consoante Koch (2003 p. 63), os links "permitem ao leitor realizar livremente desvios, fugas, saltos instantâneos para outros locais da rede, de forma prática, cômoda e econômica". Assim, em conformidade com o pensamento da autora, o leitor pode navegar de uma página para outra através desses sítios eletrônicos. 
Nessa perspectiva, Xavier (2012, p. 171), acrescenta, com relação ao hipertexto, que "ler o mundo tornou-se virtualmente possível, haja vista que sua natureza imaterial o faz ubíquo por permitir que seja acessado em qualquer parte do planeta, a qualquer hora do dia e por mais de um leitor simultaneamente". Assim, através dos links, o leitor pode acessar os documentos em qualquer lugar e esses documentos podem conter textos, imagens, sons, vídeos que a um simples botão de um mouse pode-se conectá-los a outros documentos infinitamente. Segundo Coscarelli (2006, p. 66):

Os hipertextos, por sua vez, normalmente contam ou podem contar com a presença de imagens, ícones, outras marcas (como os hiperlinks), as barras de rolamento, diferentes formas de mostrar que um botão está ou não ativado, sons, gráficos, animações, vídeos, entre outros.

Dias (2004), por sua vez, entende hipertexto como um meio de informação que existe on-line. Sob essa perspectiva, o hipertexto possui uma estrutura composta por blocos de informações interligados través de links, os quais oferecem, para o usuário, diferentes trajetos para a leitura, de forma não linear.

Tecnicamente, um hipertexto é um conjunto de nós ligados por conexões. Os nós podem ser palavras, páginas, imagens, gráficos ou partes gráficas, sequências sonoras, documentos complexos que podem eles mesmos ser hipertextos. Os itens de informação não são ligados linearmente, como em uma corda conosco, mas cada um deles, ou a maioria, estende suas conexões em estrela, de modo reticular. Navegar em um hipertexto significa, portanto, desenhar um percurso em uma rede que pode ser tão complicada quanto possível. Isso porque cada nó pode conter uma rede inteira (LÉVY, 2011, p. 20).

No enfoque funcional, Levy (2011, p. 20) compreende que "[...], um hipertexto é um conjunto de programa para a organização de conhecimentos ou dados, a aquisição de informação e a comunicação". Nesse aspecto, Marcuschi (2001, p. 96) assimila que:

Na realidade, com o hipertexto, tem-se a impressão de uma autoria coletiva ou de uma espécie de coautoria. A leitura se torna, simultaneamente, uma escritura, já que o autor não controla mais o fluxo da informação. O leitor determina não só a ordem da leitura, mas o conteúdo a ser lido. Embora o leitor usuário do hipertexto 
(hipernavegador) não escreva o texto no sentido tradicional do termo, ele determina o formato da versão final do seu texto, que pode ser diversa daquela proposta pelo autor.

Assim, o leitor define sua busca a partir dos assuntos de seu interesse. Para Marcuschi (2012, p. 3) "o hipertexto oferece uma multiplicidade de caminhos a seguir, podendo ainda o leitor incorporar seus caminhos, inserindo informações novas". O leitor, no momento da sua pesquisa, pode decidir qual conteúdo acessará, dependendo do seu interesse e do que está procurando ou pesquisando.

Dessa forma, o leitor determina tanto a ordem como o conteúdo a ser lido, bem como o percurso da leitura[2] através das escolhas que irão levá-lo a produção do conhecimento. O hipertexto consegue integrar notas, citações, bibliografias, referências, imagens, fotos e outros elementos encontrados na obra impressa de modo mais eficaz, redefinindo as funções constituintes do texto clássico. Assim, esses elementos podem ser acessados através de links.

No processo do letramento digital, o hipertexto é constituído de interatividade, momento em que o leitor se depara com informações textuais que são combinadas com imagens e sons. Assim, "com o hipertexto observa-se uma mudança não só na forma e no espaço da escrita, como também na leitura" (MAGNABOSCO, 2009, p. 54). Segundo o autor:

Sendo a prática da leitura e da escrita realizada agora por meio da tela do computador, introduzem-se não só novas formas de acesso à informação, como também novos processos cognitivos, novas formas de conhecimento, novas maneiras de ler e escrever, enfim, um novo letramento, isto é, um novo estado ou condição para aqueles que exercem práticas de escrita e leitura por meio da tela do computador (MAGNABOSCO, 2009, p. 57-58).

Nesse contexto, o leitor passa a ser também o autor do seu texto, através do processo de construção de significados, inserindo suas habilidades de autor, o que o torna coautor. Tal processo ocorre na medida em que, com estratégias de busca e construção do conhecimento, o leitor intervém nos caminhos que o texto oferece. Para Gadamer (2008), quem quiser compreender um texto, deve estar pronto a deixar que ele Ihe dê alguma informação. Isso significa que a interpretação de um texto não é 
uma comunicação entre pessoas - autor e intérprete-, mas a participação no tema que o texto comunica.

Chartier (1994) considera o texto na tela como uma revolução do espaço da escrita que altera fundamentalmente a relação entre leitor e texto, seja pelas maneiras de ler, seja pelos processos cognitivos. Assim:

Abrem-se possibilidades novas e imensas, a representação eletrônica dos textos modifica totalmente a sua condição: ela substitui a materialidade do livro pela imaterialidade de textos sem lugar específico; às relações de contiguidade estabelecidas no objeto impresso; ela opõe a livre composição de fragmentos indefinidamente manipuláveis; à captura imediata da totalidade da obra, tornada visível pelo objeto que a contém; ela faz suceder a navegação de longo curso entre arquipélagos textuais sem margens nem limites. Essas mutações comandam, inevitavelmente, imperativamente, novas maneiras de ler. Novas relações com a escrita, novas técnicas intelectuais (CHARTIER, 1994, p. 100-101).

$\mathrm{Na}$ perspectiva do letramento digital, essas características contribuem para uma nova prática de leitura e de escrita no ambiente virtual marcado especialmente pela não linearidade do texto. Nessa conjuntura, Ribeiro (2005, p. 126):

As tecnologias digitais fundaram novas maneiras de escrever e ler, utilizando interfaces novas: o teclado e o monitor em vez da caneta e do papel, a impressora, a utilização de softwares tais como Word, o bloco de notas, os navegadores para a leitura na Internet.

Nesse contexto, a tela do computador é vista como suporte e os sites como gêneros textuais e ferramentas digitais com som, imagens, animação, através de recursos de interfaces que lançam mão da interação síncrona e assíncrona em qualquer tempo e lugar. Sobre esse aspecto, diz Soares (2002, p.151):

A tela como novo espaço da escrita traz significativas mudanças nas formas de interação entre o escritor e leitor, entre escritor e texto, entre leitor e texto, novas formas de conhecimento, novas maneiras de ler e escrever, isto é, um novo estado ou condição para aqueles que exercem práticas de leitura e escrita na tela.

De acordo com Araújo Júnior e Marquesi (2009, p. 6), "[...] o hipertexto reconstitui a relação entre autor e leitor, de modo que este, ao navegar pelo hipertexto, incorpora 
as habilidades de escrita e torna-se coautor. Isso acontece na medida em que, com total autonomia, os leitores intervêm nos caminhos e vias que o texto oferece". Essa autonomia, produto da não linearidade, possibilita o leitor/escritor avançar na produção do conhecimento explorando os diversos espaços que o texto oferece.

O hipertexto não obedece a uma única ordem a ser lido, pois a leitura pode se dar através de várias formas, por meio da não linearidade. Há, também, uma maior liberdade de navegação pelas informações concentradas nas redes digitais.

Para Lévy (1996), a abordagem mais simples do hipertexto, que não exclui nem os sons nem as imagens, é a de descrevê-lo, por oposição a um texto linear, que é um texto estruturado em rede. O hipertexto seria constituído de nós (os elementos de informação, parágrafos, páginas, imagens, sequências musicais etc.) e de ligações entre esses nós (referências, notas, indicadores e "botões" que efetuam a passagem de um nó para outro).

Dessa maneira, os nós que ligam o hipertexto podem ser palavras, páginas, imagens, gráficos, sequências sonoras, documentos, entre outros. Os links remetem a outras páginas dentro do site ou em outros sites que não estão necessariamente interligados (LEVY, 2011). Através do hipertexto, pode-se navegar em um oceano de sites que estão interligados a outros sites. Conforme Marcuschi (1999, p. 8):

O hipertexto não é um gênero textual, nem um simples suporte de gêneros diversos, mas um tipo de escritura. É uma forma de organização cognitiva e referencial cujos princípios constituem um conjunto de possibilidades estruturais que caracterizam ações e decisões cognitivas [...]. Nele, não se observa uma ordem de construção, mas possibilidades de construção textual plurinearizada.

A escritura, segundo Derrida (1995), sempre foi um meio ou uma relação para ler ou para escrever, para reunir significações, reconhecer temas, ordenar constâncias correspondências. Essa nova linguagem, que não é apenas escrita fonética e transcrição de palavras, mas escrita hieroglífica[3], permite que os elementos fonéticos se coordenem em elementos visuais, picturais, plásticos. 
A construção do texto e da leitura no hipertexto se dá através da tela do computador. Para Dias (2004, p. 6):

O hipertexto altera fundamentalmente nossa noção de textualidade, pois se constitui num texto plural, sem centro discursivo, sem margens, sendo produzido por um ou vários autores e, com texto eletrônico, está sempre mudando e recomeçando, de forma associativa, cumulativa, multilinear e instável.

A esse respeito, Koch (2003, p. 63) entende que "o hipertexto constitui um suporte linguístico-semiótico, intensamente utilizado, nos dias atuais, para estabelecer interações virtuais". Já para Marcuschi (1999, p. 1), trata-se de um "processo de leitura/escrita multilinearizado, multissequencial e não determinado, realizado em um novo espaço - ciberespaço". O hipertexto digital seria, portanto, uma coleção de informações multimodais dispostas em rede para a navegação rápida e "intuitiva" (LÉVY, 1996). Em resumo, é possível falar em uma nova maneira de ler e escrever no ambiente digital.

Portanto, a hipertextualização dos documentos pode ser definida como a mistura das funções de leitura e de escrita. Assim, a escrita e a leitura trocam seus papéis e, a partir do hipertexto, toda leitura torna-se um ato de escrita (LÉVY, 1996). Dessa forma, a cada interação do leitor, o texto se transforma, produzindo um novo texto.

Quando um leitor se desloca na rede de microtextos e imagens de uma enciclopédia, deve traçar fisicamente seu caminho nela, manipulando volumes, virando páginas, percorrendo com seus olhos as colunas, tendo em mente a ordem alfabética. [...] o hipertexto é dinâmico, está perpetuamente em movimento. Com um ou dois cliques, obedecendo, por assim dizer, ao dedo e ao olho; ele mostra ao leitor uma de suas faces, depois outra, um certo detalhe ampliado, uma estrutura complexa esquematizada. Ele se redobra e desdobra à vontade, muda de forma. Não é apenas uma rede de microtextos, mas sim um grande metatexto de geometria variável, com gavetas, com dobras. Um parágrafo pode aparecer e desaparecer sob uma palavra, três capítulos sob uma palavra do parágrafo, um pequeno ensaio sob uma das palavras destes capítulos, e assim virtualmente sem fim, de fundo falso em fundo falso (LÉVY, 2011, p. 40).

Ainda segundo o autor, o hipertexto permite que "ao ritmo regular da página se sucede o movimento perpétuo de dobramento e desdobramento de um texto em 
caleidoscópico" (LEVY, 2011, p. 41). Logo, o hipertexto remete sempre a diversas informações estruturadas entre si, o que nos leva os indivíduos a desenvolverem conhecimentos em relação aos assuntos pesquisados.

\section{GÊNEROS DIGITAIS E AMBIENTE VIRTUAL}

Com o crescimento do uso do hipertexto digital e de suas principais características, como a possibilidade de interatividade, pode-se dizer que houve significantes transformações na recepção do texto e nos aspectos que demarcam a estrutura entre escritor/autor e leitor, entre escritor/autor e texto e entre leitor e texto.

Segundo Marcuschi (2012), os gêneros textuais são fenômenos históricos, profundamente vinculados à vida cultural e social, ou seja, os gêneros fazem parte de nossas vidas. Isso implica a ideia de que, consequentemente, os gêneros são adeptos às transformações da humanidade, integrando-se socialmente à cultura na qual está sendo exposto, surgindo, assim, a necessidade de adaptação e o aparecimento desses novos gêneros.

Os gêneros se estabelecem como um fenômeno histórico e social e não podem ser compreendidos de forma isolada ou individual. Assim como outros gêneros, configuram-se fundamentado em parâmetros sociais, os quais, na perspectiva sóciohistórica, na produção de um gênero, iniciarão sempre uma interação determinada e regulada pela organização enunciativa da situação de produção. Convém ressaltar, nesse último aspecto, que tais situações são definidas por alguns parâmetros sociais, que segundo Costa (2005), são:

a) O lugar social da interação (sociedade, instituição, esfera cultural, tempo histórico);

b) Os lugares sociais dos interlocutores ou enunciadores (relação hierárquica e interpessoal, relação de poder e dominação...);

c) Finalidade de interação (intenção comunicativa do interlocutor).

Com o desenvolvimento tecnológico, novos suportes e gêneros são adaptados ou criados, no intuito de dar suporte a essas tecnologias. Assim, "gêneros digitais" é o 
nome dado a uma nova modalidade de gêneros textuais, que surgiu com a Internet, dentro do hipertexto, o que viabilizou a criação de novos espaços para a escrita, possibilitando um hibridismo entre a escrita e a leitura.

$\mathrm{Na}$ tentativa de compreender esses novos gêneros, Marcuschi (2012), identifica os ambientes virtuais e os diferencia dos gêneros em vários sentidos, pois aqueles os abrigam e, por vezes, condicionam-nos, de modo a fundamentá-los na Internet, adquirindo características próprias.

Pode-se acrescentar, a essa classificação, o Ambiente de Aprendizagem Virtual (AVA). Na distinção entre ambientes virtuais e gêneros digitais, entende-se que o ambiente suporta o gênero. Ademais, convém salientar, é nesse ambiente que os gêneros digitais surgem e se desdobram.

O ambiente virtual tem como característica principal a integração de mais de um tipo de recurso de linguagem, tais como: visual, sonora, verbal, de animação, as quais podem caracterizar-se como multimodalidade, integrando novas interfaces tanto de comunicação quanto de linguagem.

Com o desenvolvimento doa ambientes virtuais, houve uma alteração dos gêneros textuais impressos para os digitais. $\mathrm{Na}$ Internet, nota-se um constante aumento desses novos gêneros digitais, tais como: blogs, e-mails, chats, fóruns, listas de discussão, entre outros. Compreende-se que:

Os ambientes virtuais possibilitam não apenas interação com textos escritos (sic), essa nova linguagem digital inclui também a habilidade de construir sentido em textos multimodais, ou seja, que mesclam palavras, imagens e sons em um mesmo espaço (ARAÚJO, 2011, p. 633).

Na utilização dos gêneros digitais na Educação, Magnabosco (2009, p. 58) entende que eles "podem ser valiosas ferramentas educacionais para o processo de ensino e aprendizagem". Isso pelo fato de eles terem:

Condições específicas e as finalidades de cada campo, não só pelo seu conteúdo (temático) e pelo estilo da linguagem (seleção de recursos 
lexicais, fraseológicos e gramaticais da língua), mas por sua construção composicional (BAKHTIN, 2003, p. 261).

Assim, esses gêneros apresentam conteúdos temáticos, estilo e de construção, o que significa a apropriação, pelos indivíduos, da forma e do conteúdo de diversos gêneros textuais presentes na sociedade. Logo, os gêneros digitais são importantes para a construção do desenvolvimento das competências discursivas dos indivíduos, mais especificamente no contexto do letramento digital.

Hodiernamente, existem novas modalidades de práticas sociais de leitura e escrita proporcionadas pela recente tecnologia da comunicação eletrônica (SOARES, 2002). Contudo, Xavier (2002, p. 3-4) alerta que o letramento digital "requer que o sujeito assuma uma nova maneira de realizar as atividades de leitura e escrita" no ambiente virtual. Soares (2002, p. 146), a esse respeito, salienta que:

Estamos vivendo, hoje, a introdução, na sociedade, de novas e incipientes modalidades de práticas sociais de leitura e de escrita, proporcionadas pelas recentes tecnologias de comunicação eletrônica computador, a rede (a web), a Internet.

Os gêneros emergentes apresentam características semelhantes aos impressos, com a evolução das tecnologias digitais ocasionou o desenvolvimento de novas práticas digitais. Na Internet, a cada minuto, são criadas novas redes, novas informações são produzidas, permitindo surgir uma nova inteligência coletiva, uma nova forma de interação e de leitura através de hipertextos e de seus links.

Para Crescitelli (2014, p. 361-362):

O indivíduo precisa conhecer as TICs para reunir condições de direcionar seu uso em favor dos seus objetivos, seja no âmbito profissional, seja no pessoal ou escolar, mas, para isso, depende de habilidades e competências específicas que the permitam exercer práticas de escrita e de leitura em contexto on-line.

De acordo com Pinheiro (2008), tem acontecido uma crescente integração e diversidade significativas no modo de construir sentidos. Consequentemente, o textual também se associou ao visual, ao áudio, ao espacial, ao comportamental, e assim por diante, é particularmente importante na hipermídia eletrônica. 
Marcuschi (2012) aponta três aspectos que tornam relevante a análise dos gêneros digitais:

a) Seu franco desenvolvimento e um uso cada vez mais generalizado;

b) Suas peculiaridades formais e funcionais, não obstante terem eles contrapartes em gêneros prévios;

c) A possibilidade que oferecem de se rever conceitos tradicionais, permitindo repensar nossa relação com a oralidade e a escrita.

Esses novos gêneros digitais permitem analisar os efeitos das novas tecnologias na linguagem e também o papel dessa última nessas tecnologias, principalmente no que se refere ao comportamento que os indivíduos adquirem com a utilização desses meios de comunicação.

De fato, os ambientes virtuais incorporam alguns gêneros presentes em outras mídias. Todavia, pode-se observar o surgimento de novos modelos, uma vez que elas sofrem alterações e são capazes de reunir vários recursos que permitem uma integração entre a escrita e a leitura.

Assim, "há uma pluralidade de textos e de leituras que se apresenta de modo multimidiático, multissemiótico, multimodal, polissêmico" (SILVA, 2005, p. 9). Esses textos, apesar de terem alguma semelhança com gêneros já existentes, não são os mesmos, são gêneros originais, com qualidades linguísticas, enunciativas, discursivas e pragmáticas próprias.

Os novos gêneros são definidos pela combinação de textos híbridos (oralidade, escrita, animação), que tem por objetivo facilitar a redação de mensagens ou de textos e sua interatividade.

Para Araújo (2008, p. 9):

Os gêneros virtuais imersos na Internet e suportados pelos sites apresentam-se como espaço da escrita diferenciado, os quais não possuem limitações geográficas e temporais, pautados numa lógica multidimensionada que permite ao leitor/escritor coordenar seu acesso 
às informações conforme preferências pessoais, de acordo com seus interesses, bem como interagir na produção de informação.

Os gêneros digitais levam o leitor/escritor a uma nova prática de leitura e escrita, proporcionando, através da interação, a cada indivíduo, a construção de seu contexto de informação. Para Marcuschi (2012, p. 16), "todos os gêneros ligados na Internet são eventos textuais baseados na escrita. Na Internet, a escrita continua essencial, apesar da integração da imagem e do som".

Nesse ínterim, a produção de um novo gênero textual estará sempre relacionada à interação social, ao local dos interlocutores e a finalidade dessa interação (DIAS, 2009). Portanto, a escrita continua como principal meio de comunicação nesses ambientes.

$\mathrm{Na}$ tentativa de compreender essa relação entre gêneros, Marcuschi (2012) procura determinar a relação entre os gêneros emergentes e suas contrapartes pré-existentes, estabelecendo alguns novos gêneros. O autor analisa os gêneros emergentes do ambiente virtual, bem como apresenta os gêneros mais conhecidos e quem têm sido estudados no momento.

Através da comparação entre gêneros virtuais emergentes e suas contrapartes não virtuais já conhecidas, estabelecem-se doze novos gêneros digitais, a saber: e-mail, chat em aberto, chat reservado, chat ICQ (agendado), chat em salas privadas, entrevista com convidado, e-mail educacional (aula por e-mail), aula chat (aulas virtuais), vídeo conferência interativa, lista de discussão, endereço eletrônico e jornal digital (MARCUSCHI, 2012).

A Internet é vista como um espaço emergente de novas tecnologias digitais que proporciona um novo processo de produção e compreensão textual. Ela apresenta características próprias que juntam a escrita e a leitura em um único processo, eliminando, assim, a fronteira de ler e escrever. Conforme sugere Souza (2001, p. 33), a linguagem utilizada na Internet:

É escrita por valer-se de grafemas e ser passível de registro e armazenamento, possuindo, potencialmente, a permanência que 
caracteriza toda comunicação escrita. Ao mesmo tempo, ela aproximase do discurso oral por suas possibilidades quanto à interatividade, por nela podermos identificar traços de organização de troca de turnos, pelo discurso ser construído conjuntamente e localmente pelos interagentes, e por ele ter sua forma influenciada pela pressão do tempo, tal como acontece na conversação. Ela assemelha-se à conversação, também, por recorrer, ainda que semioticamente, à contextualização paralinguística, por seus usuários parecerem necessitar tão insistentemente transportar para a tela do computador suas risadas, tons de voz e expressões faciais.

A linguagem utilizada na Internet apresenta característica comuns a toda comunicação escrita e, ao mesmo tempo, aproxima-se da oralidade, através da sua interação. Para Silveira e Motta (2011, p. 2), os gêneros digitais podem ser:

Entendidos como textos emergentes no contexto de tecnologia digital. Suas características se assemelham às dos gêneros tradicionalmente conhecidos nas várias formas de comunicação e nas práticas de linguagem escrita na sociedade.

Esses gêneros emergentes evidenciam uma relação com outros gêneros textuais já existentes. Entretanto, esses novos gêneros foram configurados para um discurso eletrônico e, desta forma, apresentam características particulares e próprias presentes na mídia virtual. A esse respeito, Marcuschi (2012) propõe que, no ambiente virtual, há diversos gêneros emergentes, como e-mails, chats, blogs. Esses gêneros possuem estreita relação com gêneros textuais já existentes em outros ambientes. Todavia, estão dispostos em meio eletrônico e, portanto, apresentam características próprias presentes nesses ambientes.

Essa revolução possibilitou uma maior interação entre os usuários do ambiente virtual, conduzindo-os a uma nova prática de leitura e escrita, a um novo letramento. Para Ramal (2002, p. 14), "os suportes digitais, as redes, os hipertextos são, a partir de agora, as tecnologias intelectuais que a humanidade passará a utilizar para aprender, gerar informação, ler, interpretar a realidade e transformá-la".

Essas mudanças no suporte de leitura e escrita, ou seja, o suporte digital, a tela do computador - monitor, smartfones, tablets, foram proporcionados através da utilização das TICs. Silva (2011, p. 31) diz que: 
As TICs estão exigindo leitores e produtores de textos criativos, dinâmicos e participativos, capazes de interagir com a diversidade de mídias e com superabundância de informação no mundo digital. Computadores, celulares, TVs, máquinas fotográficas digitais, redes sociais, jogos digitais [...] mediados pelos dispositivos eletrônicos e pelas mídias digitais.

Esses novos suportes tecnológicos levam a uma nova prática no processo de aprendizagem da escrita e da leitura, através de textos, hipertextos, que demandam uma nova prática nesse processo. Neste contexto, Lévy (1996, p. 43) compreende que:

O suporte digital permite novos tipos de leituras (e de escritas) coletivas. Um continuum variado se estende assim entre a leitura individual de um texto preciso e a navegação em vastas redes digitais no interior dos quais um grande número de pessoas anota, aumenta, conecta os textos uns aos outros por meio de ligações hipertextuais.

Nesse novo ambiente virtual, Silva (2011, p. 32) considera que:

Leitores e autores assumem novos contratos comunicativos, praticando a leitura e a escrita de modo multissequencial, acessando homepages, ambientes virtuais e interfaces digitais, clicando em links que abrem novas possibilidades de leitura, construindo blogs, escrevendo comentários e recados nas redes sociais, além de uma infinidade de situações que redimensionam o ler e o escrever no ciberespaço.

Assim, no texto eletrônico, "a distância entre autor e leitor se reduz porque o leitor se torna, ele também, autor, tendo liberdade para construir, ativa e independentemente, a estrutura e o sentido do texto" (SOARES, 2002, p. 154). Define-s, portanto, um novo comportamento interativo.

O desenvolvimento de novas práticas de leitura e de escrita marcadas pelas diferentes atividades no ambiente virtual compreende e leva os interlocutores ao letramento digital, permitindo com que eles adquiram a habilidade que norteia o uso dos recursos em diferentes suportes das Tecnologias de Informação e Comunicação.

Diante das características dos novos gêneros e ambientes digitais, a linguagem disseminada nesses ambientes, representa uma tentativa de interações face a face, mediada pelo uso das novas tecnologias. Assim, as práticas de leitura e de escrita 
são moldadas para as práticas sociais existentes na sociedade em que o indivíduo está inserido.

Marcuschi (2012) considera que há uma variedade de novos gêneros, como e-mail, chats, entrevistas, fóruns de discussão e blogs na internet. Esses gêneros emergentes apresentam uma estreita relação com outros gêneros textuais já existentes. Contudo, esses novos gêneros foram configurados para um discurso eletrônico e, desse modo, apresentam características particulares e próprias da mediação presente na mídia virtual.

A seguir abordaremos as características de alguns dos gêneros virtuais que emergiram com a expansão da internet:

E-mail (carta eletrônica): correio eletrônico com formas de produção típicas e já padronizadas é um espaço de interação assíncrono, o qual possibilita que sejam enviadas mensagens eletrônicas para um ou mais usuários. Esses usuários podem recortar, colar, copiar, encaminhar, anexar, adicionar alguma outra informação. A linguagem varia de acordo com o conteúdo, podendo ser formal ou informal.

Correio eletrônico ou e-mail é uma forma de comunicação escrita normalmente assíncrona de remessa de mensagens entre os usuários do computador. Em certas circunstâncias, ele pode apresentar uma defasagem mínima de tempo entre uma remessa e a resposta, dando a nítida sensação de turnos em andamento, quando ambos estão em conexão on-line, ou então ter defasagem de dias, semanas e meses. No geral, os interlocutores são conhecidos ou amigos e raramente ocorre o anonimato, que é uma violação de normas do gênero (tal como uma carta anônima). Esta característica o diferencia dos bate-papos. Por outro lado, os e-mails em geral são pessoais, o que os diferencia das listas de grupos ou fóruns de discussão (MARCUSCHI, 2012, p.16).

Chats (bate-papo): espaço on-line de interação síncrono, em que o usuário poderá conversar (com hora marcada) com outros usuários que estão escritos na mesma sala. Essas conversas podem ser abertas a todos os usuários do chat ou privada para apenas dois usuários previamente selecionados. Tais usuários podem continuar vendo a conversa do grupo. A linguagem é bem objetiva, com frases curtas, podendo ser formal ou informal, "produções escritas no formato de diálogo numa sequência 
imediata e retornos rápidos com o sistema de seleções de parceiros, podendo ocorrer muitas confusões de multiplicidade de indivíduos na sala" (MARCUSCHI, 2012, p.21).

Blog (diário virtual): diários on-line no qual o responsável publica histórias, notícias, ideias. O espaço é de interação assíncrono de cunho pessoal, em que o usuário tem liberdade para escrever e inserir figuras de conteúdo diverso. A linguagem é informal e aberta a interferência dos demais usuários.

Marcuschi (2012) salienta que, a princípio, os blogs tinham a função de registrar as leituras que se realizavam pela internet, tornando-se uma espécie de diário de bordo. O autor ainda considera que:

Os blogs têm uma história própria, uma função específica e uma estrutura que os caracteriza como um gênero, embora extremamente variados nas peças textuais que albergam. Hoje eles são praticados em grande escala e estão fadados a se tornarem cada vez mais populares pelo enorme apelo pessoal (MARCUSCHI, 2004, p. 61).

Dessa forma, esses gêneros digitais, com suas principais características, têm contribuído para novas formas de ler e escrever e se comunicar no mundo digital.

\section{CONSIDERAÇÕES FINAIS}

Diante do advento da Internet e do desenvolvimento das novas tecnologias de informação e comunicação, os quais possibilitam o surgimento de diversos recursos e ferramentas no contexto digital, o hipertexto é visto como nós conectados a links de acesso a textos que nos remetem a outras páginas, através de uma leitura/escrita não linear e não sequencial na qual o leitor pode definir a trajetória a seguir.

Nesse contexto, com o desenvolvimento do hipertexto digital, novos gêneros são adaptados ou criados com fundamentos e características próprias no ambiente digital. Esses novos gêneros digitais apresentam particularidades relevantes e são definidos pela combinação de textos híbridos (oralidade, escrita, animação), que têm por objetivo facilitar a redação de mensagens ou textos e sua interatividade. 
Portanto, percebe-se que o hipertexto é dinâmico, interativo, não linear, está sempre em movimento e, ao simples clique de um mouse, ele apresenta ao interlocutor uma imensa possibilidade de acesso a links. De maneira análoga, os gêneros digitais, que levam o leitor/escritor a uma nova prática de leitura e escrita e, através da interação, e do desenvolvimento das habilidades cada indivíduo passa a construir seu contexto de informação e a construção do conhecimento.

Compreende-se que a utilização intensiva das tecnologias digitais proporciona novas práticas sociais de leitura e de escrita, de interação digital entre os participantes, anteriormente não presente em nossa sociedade. Esses novos gêneros desempenham influência na produção de textos e na sua escrita, através da hibridização entre as modalidades oral e escrita.

\section{REFERÊNCIAS}

ARAÚJO JÚNIOR, Carlos Fernando de; MAERQUESI, Sueli Cristina. Atividades em ambientes virtuais de aprendizagem: parâmetros de qualidade. In: LITTO, Fredric M.; FORMIGA, Marcos (Org.) Educação à Distância: o estado da arte. São Paulo: Pearson Education do Brasil, 2009.

ARAÚJO, Elaine Vasquez Ferreira de. Internet, hipertexto e gêneros digitais: novas possibilidades de interação. Cadernos do CNLF, v. 15, n. 5, t. 1. Rio de Janeiro: CiFEFiL, 2011. p. 633-639. Disponível em: <http://www.filologia.org.br/xv_cnlf/tomo_1/55.pdf>. Acesso em: 2 abr. 2020.

ARAÚJO, Rosana Sarita. Letramento digital: conceitos e pré-conceitos.In: SIMPÓSIO HIPERTEXTO E TECNOLOGIAS NA EDUCAÇÃO: MULTIMODALIDADES E ENSINO, 2. 2008, Recife. Anais eletrônicos... Recife: UFPE, 2008. Disponível em: <https://www.ufpe.br/nehte/simposio2008/anais/Rosana-Sarita-Araujo.pdf>. Acesso em: 15 jan. 2020.

BAIRON, S. Multimídia. São Paulo: Global, 1995. 
BAKHTIN, Mikhail. Os gêneros do discurso. In: BAKHTIN, Mikhail. Estética da criação verbal. São Paulo: Martins Fontes, 2003.

BOLTER, J. D. Writing space. The computer, hypertext and the history of writing. Hillsdale: Lawrence Erlbaum Associates, 1991.

BRASILEIRO, Ada Magaly Matias; MARTINS, Renata Cristina Guimarães. A leitura hipertextual no processo de construção de conhecimento em EaD. Cadernos Cespuc. Belo Horizonte. n. 23, 2013. Disponível em: $<$ http://periodicos.pucminas.br/index.php/cadernoscespuc/article/view/8325>. Acesso em: 30 jan. 2020.

CASTELLS, Manuel. A sociedade em rede: a era da informação: economia, sociedade e cultura. São Paulo: Paz e Terra, 1999.

CHARTIER, Roger. A ordem dos livros: leitores, autores e bibliotecas na Europa entre os séculos XIV e XVIII. Brasília, DF: UnB, 1994.

COSCARELLI, Carla Viana. Entre textos e hipertextos. In: VIANA, Carla (Org.) Novas tecnologias, novos textos, novas formas de pensar. 3. ed. Belo Horizonte, 2006.

COSCARELLI, Carla Viana; RIBEIRO, Ana Elisa (Org.). Letramento digital: aspectos sociais e possibilidades pedagógicas. 3. ed. Belo Horizonte: Ceale; autêntica, 2014.

DERRIDA, Jacques. Escritura e diferença. 2.ed. São Paulo: Perspectiva, 1995.

DIAS, Maria Helena Pereira. Hipertexto: outra dimensão para o texto, outro olhar para a educação. 2004.2 Disponível em: <http://www.twiki.ufba.br/twiki/pub/GEC/TrabalhoAno2004/hipertexto_outra_dimensa o.pdf>. Acesso em: 15 jan. 2020.

FACHINETTO, Eliane Arbusti. O hipertexto e as práticas de leitura. 2005. Disponível em: $<$ http://unisc.br/portal/images/stories/mestrado/letras/coloquios/ii/hipertexto_praticas. pdf>. Acesso em: 25 jan. 2020. 
$\mathrm{KOCH}$, Ingedore G. Villaça. Desvendando os segredos do texto. 2.ed. São Paulo: Cortez, 2003.

KÖCHE, José Carlos. Fundamentos de metodologia científica: teoria da ciência e iniciação à pesquisa. Petrópolis, RJ : Vozes, 2011.

KOMESU, Fabiana. Pensar em hipertexto. 2005. Disponível em: <https://www.ufpe.br/nehte/artigos/hipertexto.pdf>. Acesso em: 20 jul. 2020

LÉVY, Pierre. As tecnologias da inteligência: o futuro do pensamento na era da informática. Rio de Janeiro: Trinta e Quatro, 2011.

LÉVY, Pierre. O que é virtual. São Paulo: Trinta e Quatro, 1996.

MAGNABOSCO, Gislaine Gracia. Hipertexto e gêneros digitais: modificações no ler e escrever? Conjectura, Caxias do Sul, v. 14, n. 2, maio/ago. 2009, p. 49-63. Disponível em: <www.ucs.br/etc/revistas/index.php/conjectura/article/viewFile/14/13>. Acesso em: 15 jul. 2020.

MARCUSCHI, Luiz Antônio. O hipertexto como um novo espaço da escrita em sala de aula. Linguagem \& Ensino, v. 4, n. 1, 2001. p. 79-111. Disponível em: <http://www.ufrgs.br/limc/escritacoletiva/pdf/hipertexto_como_novo_espaco.pdf>. Acesso em: 15 jul. 2020.

MARCUSCHI, Luiz Antônio. Gêneros textuais emergentes no contexto da tecnologia digital. In: MARCUSCHI, Luiz Antônio; XAVIER, Antonio Carlos (Org.). Hipertexto e gêneros digitais: novas formas de construção de sentido. 3. ed. São Paulo Cortez, 2012.

MARCUSCHI, Luiz Antônio. Linearização, cognição e referência: o desafio do hipertexto. 1999.

em: $<$ http://web.uchile.cl/facultades/filosofia/Editorial/libros/discurso_cambio/17Marcus.pd f>. Acesso em: 30 jan. 2020. 
PINHEIRO, Petrilson Alan. Gêneros digitais construindo e sendo construídos por gêneros discursivos: repensando as práticas do letramento. 2008. Disponível em: $<$ http://dlcv.fflch.usp.br/sites/dlcv.fflch.usp.br/files/12.pdf>. Acesso em: 02 abr. 2020.

RAMAL, Andrea Cecilia. Educação na cibercultura - hipertextualidade, leitura, escrita e aprendizagem. Porto Alegre: Artmed, 2002.

RIBEIRO, Ana Elisa. Os hipertextos que Cristo leu. 2005. p. 124-130. Disponível em: <https://lidiacassia.files.wordpress.com/2013/07/hipertextos_cristo_leu.pdf>. Acesso em: 15 set. 2020.

SILVA, Ivanda Maria Martins. Tecnologias e letramento digital: navegando rumo ao desafio. Edu. Tem. Dig., Campinas, v. 13, n. 1, jul./dez. 2011, p. 27-43. Disponível em: <http://www.ssoar.info/ssoar/bitstream/handle/document/28612/ssoar-etd-20111-silva-tecnologias_e_letramento_digital.pdf?sequence=1 >. Acesso em: 15 set. 2020.

SILVA, Obdália. S. Tecendo os fios da experiência dos professores de língua portuguesa: do texto do paple ao texto digital. XII EPENI, 2005.

SILVEIRA, Vitor Luiz da; MOTTA, Marise Ferreira da. Gêneros textuais em ambiente virtual. In: GONZALEZ, Marcos; MOLLICA, Maria Cecilia (Org.). Linguística e ciência da informação: diálogos possíveis. Curitiba: Appris, 2011.

SOARES, Magda. Novas práticas de leitura e escrita: letramento na cibercultura. Educ. Soc., Campinas, v. 23, dez. 2002, p. 143-160. Disponível em: <http://www.scielo.br/pdf/es/v23n81/13935.pdf>. Acesso em: 15 jan. 2020.

SOUZA, Ricardo Augusto de. O discurso oral, o discurso escrito e o discurso eletrônico. In: PAIVA, Vera Lúcia M. de O. (Org.). Interação e aprendizagem em ambiente virtual. Belo Horizonte: Ed. da UFMG, 2001.

XAVIER, Antonio Carlos dos Santos. Letramento digital e ensino. 2002. Disponível em: <https://www.ufpe.br/nehte/artigos/Letramento\%20digital\%20e\%20ensino.pdf>. Acesso em: 25 set. 2020. 
XAVIER, Carlos Antônio. Leitura, texto e hipertexto. In: MARCUSCHI, Luiz Antônio; XAVIER, Antonio Carlos (Org.). Hipertexto e gêneros digitais: novas formas de construção de sentido. 3. ed. São Paulo Cortez, 2012.

\section{APÊNDICE - REFERÊNCIAS DE NOTA DE RODAPÉ}

2. São construções linguísticas e textuais para que o autor consiga alcançar o sentido da constituição do texto, além de poder compreender e definir o fluxo de sua leitura a partir dos assuntos relacionados ao texto.

3. Hieroglífica, escrita baseada em desenhos e símbolos que representam ideias, conceitos e objetos.

Enviado: Junho, 2020.

Aprovado: Outubro, 2020. 